provide some background for clinicians new to the field. The section giving detailed instructions for the carrying out of the various tests is excellent. A valuable list of references and a good index are provided.

$$
\text { G. LOEWI }
$$

TEXTBOOK OF VIROLOGY, 4th ed. By A. J. Rhodes and C. E. von Rooyen. (Pp. 600; 86 figures; 85 tables. 108s.) Baltimore: Williams and Wilkins Company. 1962.

The last edition of this well-known textbook was published in 1958. In the intervening four years advances in medical virology have been so rapid that the book has had to be completely rewritten. The major part of the revision has been carried out by the authors and the essential character of the book remains the same, but in this latest edition they have been assisted by five contributors who have undertaken the revision of special sections of the book. The end-result is quite exceptionally good, and there is no doubt that the authors have achieved their chief purpose to present an up-to-date account of medical virology suitable for students and practitioners of medicine, public health, microbiology, and other public health sciences.

The main change is that the chapters have been completely re-arranged; no longer are they grouped according to clinical and epidemiologial features but instead they have been re-arranged according to biological and antigenic properties of the causative viruses. On the whole this change has worked out quite well. The first 10 chapters deal with fundamental properties, technical methods, pathology, pathogenesis, and immunity wi special chapters on cell culture by K. R. Rozee, on statistical methods by B. W. Reid, and on tumour virusgs by L. Siminovitch. They are all excellent, informative and up to date and set the standard for the rest of the book. Here will be found concisely set out the answers to mafyy everyday problems on viruses.

The next 15 chapters deal with several groups $\mathbb{\Phi}_{f}$ viruses, herpes virus, poxvirus, myxovirus, and other respiratory infections and hepatitis. They give a clear idea of the rapid progress that has been made. D. M. Mcleaf, of Toronto, brings up to date what is known about the arborviruses. This section of 20 chapters is a veritabe mine of information and superbly well written and illstrated.

The chapters on the enterovirus group provide a excellent review of the general properties of these viruses and their clinical syndromes. Poliomyelitis is discussed by A. J. Beale in a comprehensive chapter which coveiss the recent and important developments in methods of prevention.

The illustrations and tables are uniformly excellent but the method of numbering them according to chapteffs instead of in consecutive order seems rather pointles. This new edition, which is extremely well produced, maintains the high standards of previous editions. It is strongly recommended to those for whom it is intendes It will be found a most useful book to have around affd should certainly be readily available in every hospital laboratory.

\title{
The College of Pathologists
}

\author{
MEMBERSHIP WITHOUT EXAMINATION
}

FOUNDER MEMBERSHIP Applications from those eligible will be considered up to 30 April 1964. The names of some 1,100 senior pathologists have now been accepted by Council.

MEMBERSHIP A According to the Articles of Association, medically qualified pathologists reaching consultant status or its equivalent during the three-year period April 1963-66 will automatically be eligible for admission to Membership.

B The Council now intends to proceed to consider application by those who have not yet reached consultant status or its equivalent, but whose training and experience would appear to exempt them from the whole or part of the forthcoming examination for Membership.
Application is now invited from pathologists, other than those undergoing training, who have held established hospital, teaching, or whole-time resear $\overline{\bar{k}}$ appointment for five or more years.

の

Each of those wishing to claim exemption will considered on an individual basis: such applicatiop should be made as soon as possible and, in any event, not later than 30 April 1964.

C In certain circumstances, Membership may $\frac{0}{\overline{5}}$ granted to those submitting published works on pathology or related subjects adjudged to be of sufficient distinction.

Application forms and further information may obtained from the Registrar, The College of Pathologisf 12 Grosvenor Crescent, London, S.W.1. 